\title{
Erratum to: Increasing the Resistance of Scuffing for HCR External Helical Gearing
}

\author{
M. Rackov, M. Čavić, M. Penčić and M. Verě̌
}

\section{Erratum to:}

Chapter "Increasing the Resistance of Scuffing for HCR External Helical Gearing”' in: I. Doroftei et al. (eds.),

New Advances in Mechanism and Machine Science, Mechanisms and Machine Science 57, https://doi.org/10.1007/978-3-319-79111-1_52

In the original version of the book, greek letter " $\rho$ " at the end of Equation 7 has to be removed in Chapter 52. The erratum chapter and the book have been updated with the change. 